\title{
Concussion management by primary care providers
}

\author{
M D Pleacher, W W Dexter
}

Br J Sports Med 2006;40:e2 (http://www.bjpportmed.com/cgi/content/full/40/1/e2). doi: 10.1136/bjsm.2005.019067

Objective: To assess current concussion management practices of primary care providers.

Methods: An 11 item questionnaire was mailed to primary care providers in the state of Maine, with serial mailings to non-respondents.

Results: Over $50 \%$ of the questionnaires were completed, with nearly $70 \%$ of primary care providers indicating that they routinely use published guidelines as a tool in managing patients with concussion. Nearly two thirds of providers were aware that neuropsychological tests could be used, but only $16 \%$ had access to such tests within a week of injury.

Conclusions: Primary care providers are using published concussion management guidelines with high frequency, but many are unable to access neuropsychological testing when it is required.

$\mathrm{R}$ ecent estimates indicate that as many as 300000 concussions occur each year during athletic competition. ${ }^{1}$ More than 62000 cases of concussion are estimated to occur among high school athletes annually. ${ }^{2}$ After a concussion, the injured brain may be vulnerable to further injury if another trauma is sustained. ${ }^{3}$ The second impact during this period of vulnerability may lead to severe cerebral oedema with potentially catastrophic neurological outcomes. ${ }^{4}$ Evidence indicates that repeated concussive injuries to the brain may lead to long term impairment of cognitive function. ${ }^{5}$ Younger athletes may be at increased risk of complications from repetitive head trauma. ${ }^{6}$

To reduce the risk of such adverse outcomes, numerous sets of guidelines have been established to aid the management of concussion. These guidelines suggest an appropriate time for the injured athlete to return to contact sports. ${ }^{7}$ The most commonly used guidelines are those published by Cantu, the Colorado Medical Society, and the American Academy of Neurology. ${ }^{8-10}$ These guidelines have been widely published, but the frequency with which they are used by primary care providers remains unknown.

Neuropsychological testing of athletes has been used to identify cognitive deficits after concussion. These tests may be used as an adjunct to existing management guidelines to assist doctors in determining an appropriate time for athletes to return to competition. Many investigators have examined the utility of cognitive testing regimens after concussion. ${ }^{11-13}$

In this study, primary care providers (paediatricians, family doctors, family nurse practitioners, and doctor's assistants) in the state of Maine were surveyed with regard to their use of published guidelines in the management of concussion. They were also asked about their current use of neuropsychological tests to evaluate athletes with concussion.

\section{MATERIALS AND METHODS}

An 11 item questionnaire was mailed to 723 primary care providers (paediatrics, family practice, nurse practitioners, and doctor's assistants) in Maine. Two subsequent mailings were made to non-respondents. Data from the survey were entered into a database, and results were analysed using standard descriptive statistics.

\section{RESULTS}

Of the 723 surveys sent, 367 (50.8\%) were completed fully. Of the 367 respondents, $209(56.9 \%)$ were family doctors, 102 $(27.8 \%)$ were paediatricians, $31(8.4 \%)$ were nurse practitioners, and $22(6 \%)$ were doctor's assistants. Just over half $(214 ; 58 \%)$ of the respondents indicated that they had treated between one and four patients with concussion in the preceding year. Only $82(22 \%)$ had not treated anyone with concussion in the preceding year. A very small proportion $(6 \%)$ of respondents routinely perform sideline coverage at sporting events. Of these 24 providers, eight (33\%) used a standardised objective sideline test such as the balance errors scoring system for athletes suspected of having a concussion.

Of the 367 respondents, 251 (68.4\%) indicated that they used published guidelines to aid the management of concussion; $55.4 \%$ of these used The American Academy of Neurology guidelines, $23.8 \%$ used the Colorado State Medical Society guidelines, and $12.5 \%$ used the Cantu guidelines.

Of the 367 respondents, $116(31.6 \%)$ indicated that they did not routinely use published guidelines for the management of concussion. A lack of awareness was usually identified as the barrier to guideline usage (71.6\%). An additional 16\% indicated that they did not use the published guidelines because they found them confusing.

Of the 367 respondents, $241(65.7 \%)$ indicated that they were aware that neuropsychological testing could be used in the management of concussion. However, only $42.8 \%$ (157/ 367 ) of respondents indicated that such testing was available locally, and only $16.1 \%$ (59/367) could reliably access such testing within a week of injury. Sixty five (17.7\%) of the 367 respondents had used neuropsychological testing in the management of concussion in the past; 52 of these $(80 \%)$ indicated that it was helpful in their management of concussion. Forty five of the latter would use neuropsychological testing again. Overall, 205/367 (55.8\%) indicated that they would be likely to use neuropsychological testing in their future management of concussion.

\section{DISCUSSION}

Although concussion management guidelines are widely published, how often they are used has not been well documented. A 1995 study by Genuardi and King ${ }^{14}$ investigated the discharge instructions given to patients admitted to hospital for sports related concussion. Only 30\% received discharge instructions that agreed with available guidelines for return to play. This suggests that, although guidelines are widely available, their use is rare. A second study, by Bazarian et al, ${ }^{15}$ showed that many primary care doctors were unaware of concussion management guidelines. The study also showed that, when doctors did implement existing guidelines, many did so inappropriately.

Our results indicate that $68 \%$ of providers in Maine use published guidelines to assist the management of concussion. 
This result compares favourably with those of Bazarian et al, ${ }^{15}$ which indicated that only $20 \%$ of survey respondents used guidelines for concussion management. The most often cited reason for failing to use guidelines in our survey was a lack of awareness of their existence. This can be overcome by providing continuing educational opportunities at meetings and conferences.

This study indicates that only a small proportion of primary care providers are involved in sideline medical coverage for sporting events. However, given the high incidence of sport related concussions among participants in contact and collision sports, perhaps more primary care providers should offer sideline coverage as a service to their communities.

Neuropsychological testing has been gaining acceptance as an adjunctive tool in the management of concussion. A recent consensus statement by the Concussion in Sport Group published in 2002 places great value on neuropsychological testing in the determination of when an athlete should be allowed to return to competition after concussion. ${ }^{16}$ Neuropsychological testing affords providers an objective measure of recovery to help in this decision. Results from our survey indicate that, although most providers are aware that neuropsychological testing can be useful in concussion management, only a small proportion have actually accessed it. Only $42.8 \%$ of providers indicated that formal neuropsychological testing was available locally, thus identifying a significant barrier to the use of such testing for the management of concussion in rural areas.

An alternative to the formal, time consuming neuropsychological testing is the use of computerised screening neuropsychological test batteries. These have the advantage of being readily available, and the results can be analysed by an athletic trainer, team doctor, or school nurse trained in the interpretation of such results. These tools can be used to assist in the return to play decision, and they can identify concussed athletes with more significant deficits who may benefit from further formal neuropsychological testing. A drawback to the commercially available computerised test batteries is their expense, which may be a barrier to their use in rural or underserved areas.

The primary care providers surveyed in this study do an outstanding job of using current guidelines in the management of concussion. Although these providers are interested in using neuropsychological testing to aid concussion management, a lack of local availability appears to be a considerable barrier. In areas where access to neuropsychologists is limited, computerised neuropsychological tests may be useful as a screening tool to identify those in need of more formal evaluation.

\section{Authors' affiliations \\ M D Pleacher, W W Dexter, Maine Medical Center, Sports Medicine, Portland, ME, USA \\ Competing interests: none declared \\ Correspondence to: Dr Pleacher, Maine Medical Center, Sports} Medicine, Portland, ME 04102, USA; pleacherm@hotmail.com

Accepted 29 March 2005

\section{REFERENCES}

1 Thurman DJ, Branche CM, Sneizek JE. The epidemiology of sports-related traumatic brain injuries in the United States: recent developments. J Head Trauma Rehabil 1998;13:1-8.
2 Powell JW, Barber-Foss KD. Traumatic brain injury in high school athletes. JAMA 1999;282:958-63.

3 Woitys EM, Hovda D, Landry G, et al. Current concepts: concussion in sports. Am J Sports Med 1999;27:676-86.

4 Cantu RC. Second impact syndrome: immediate management. Phys Sportsmed 1992;20:55-66.

5 Rabadi MH, Jordan BD. The cumulative effect of repetitive concussion in sports. Clin J Sport Med 2001;11:194-8.

6 Leclerc S, Lassonde M, Delaney JS, et al. Recommendations for grading of concussion in athletes. Sports Med 2001;31:629-36.

7 Maroon JC, Lovell MR, Norwig J, et al. Cerebral concussion in athletes: evaluation and neuropsychological testing. Neurosurgery 2000;47:659-72.

8 Cantu RC. Guidelines for return to contact sports after cerebral concussion. Phys Sportsmed 1986;14:75-83.

9 Kelly JP, Nichols JS, Filley CM, et al. Concussion in sports: guidelines for the prevention of catastrophic outcome. JAMA 1991;266:2867-9.

10 Report of the Quality Standards Subcommittee. Practice parameter: the management of concussion in sports. Neurology 1997;48:581-5.

11 Barth JT, Alves WA, Ryan TV, et al. Mild head injury in sports: neuropsychological sequelae and recovery of function. Mild head injury. New York: Oxford Press, 1989:257-75

12 Collins MW, Grindel SH, Lovell MR, et al. Relationship between concussion and neuropsychological performance in college football players. JAMA 1999;282:964-70.

13 Echemendia RJ, Putukian M, Mackin RS, et al. Neuropsychological test performance prior to and following sports-related mild traumatic brain injury. Clin J Sport Med 2001;11:23-31.

14 Genuardi FJ, King WD. Inappropriate discharge instructions for youth athletes hospitalized for concussion. Pediatrics 1995;95:216-18.

15 Bazarian JJ, Veenema T, Brayer AF, et al. Knowledge of concussion guidelines among practitioners caring for children. Clin Pediatr (Phila) 2001;40:207-12.

16 Concussion in Sport Group. Summary and agreement statement of the first international conference on concussion in sport, Vienna 2001. Phys Sportsmed 2002;30:57-63.

\section{COMMENTARY}

This study helps to shed light on the current practices in the management of sports related concussion among primary care providers in the state of Maine. It implies that most of them use published guidelines to assist in their management of patients with sports related concussion. However, as with all analysis of self reported treatment practices, it is not known how these respondents actually treat sports related concussion in their daily practice. Also of concern is the possibility of sampling error between the responders and non-responders. With concussion occurring in up to $10 \%$ of athletes in contact and collision sports per year, one has to question why over $80 \%$ of the respondents to the questionnaire treated only zero to four patients with sports related concussions in the previous year. Who is actually treating most of the athletes with sports related concussions in Maine? Does this mean that the other $19 \%$ of the primary care providers in Maine treat most of the sports related concussions, or are these injuries being taken care of by another group of providers who were either not surveyed or did not respond to the survey? What this study does indicate is that work still needs to be carried out to educate primary care providers about the use of published guidelines to aid in their management of sports related concussion, and to inform these providers about the availability and accessibility of computerised neuropsychological testing to help. These measures could ultimately improve the level of care in concussion management and contribute to the safe return to play of concussed athletes.

W M Heinz Orthopedic Associates, Portland, ME 04102, USA; wheinz@orthoassociates.com 